\title{
Abordagens ao aprendizado político
}

\author{
Paulo J. Krischke
}

Há um reconhecimento crescente entre os cientistas políticos de que uma fonte principal para a conquista e o aperfeiçoamento da democracia é o aprendizado político por parte dos atores sociais e políticos. Este reconhecimento decorre do fato de que "estamos particularmente interessados na sobrevivência das democracias emergentes - e em como evitar a recorrência de crises prevenindo o eventual colapso dessas democracias" (McCoy 2000). Podemos de antemão duvidar que o aprendizado político evitasse a recorrência de crises, ou ainda que sendo isso possível, prevenisse o eventual colapso da democracia. Mas, depois dos eventos de 11 de setembro de 2001, podemos inclusive adiantar que essa preocupação com o aprendizado político não se aplica apenas ao destino das democracias emergentes, pois abarca as alternativas de futuro dos próprios países centrais do Ocidente. Escrito antes desses eventos, o livro de McCoy já reconhece que a bibliografia especializada não considera satisfatoriamente como o aprendizado político reorienta os comportamentos e atitudes em apoio à democracia política e seu aperfeiçoamento.

Portanto, tais críticas à bibliografia são um vasto desafio para trabalho de pesquisa ainda a ser feito. E o presente texto acata esse desafio, numa revisão teórica inicial das abordagens existentes ao aprendizado político no contexto da globalização. Num primeiro momento, consideramos as limitações da abordagem ao estudo das elites nos processos de democratização da América Latina. Em segundo lugar, salientamos as dificuldades da teoria da modernização para enfrentar o tema, nos estudos sobre os públicos massivos. Mais adiante salientamos as contribuições que uma abordagem inspirada nos trabalhos de Jürgen Habermas pode proporcionar ao estudo do aprendizado político. E concluímos

\footnotetext{
${ }^{1}$ Doutor em Ciência Política pela New School, professor visitante do Programa de Pós-Graduação em Ciências Sociais da Pucrs, pesquisador do CNPq.
} 
indicando certas interfaces temáticas a serem examinadas na bibliografia no contexto da globalização.

É muito importante compreender como o aprendizado político por parte das elites afeta as instituições da democracia. Mas esse processo é mais complexo do que um modelo fundamentado apenas no auto-interesse poderia sugerir. Por exemplo, McCoy sustentou que as elites políticas da América Latina passaram a apoiar a democracia devido às experiências traumáticas vividas durante os regimes autoritários (violência, torturas, arbitrariedades) e as transições liberais que se seguiram (hiper-inflação, campanhas contra a corrupção, processos de impeachment etc.). Os quatro estudos de caso que o livro organizado por McCoy apresenta (Venezuela, Argentina, Uruguai e Chile) indicam que as elites perceberam gradualmente que a implantação e o aperfeiçoamento do regime democrático de governo seria mais benéfico e menos custoso aos seus próprios interesses, que a continuidade ou o retorno do anterior regime autoritário.

O livro argumenta que os traumatismos políticos (devidos à violação dos direitos humanos, ou a profundas crises da economia) resultam em aprendizado, que pode ser tanto "instrumental" como "complexo", na escolha pela democracia. Quando o processo de aprendizado é principalmente instrumental, tende a centrar-se nas causas mais importantes do trauma, esforçando-se por evitá-las no futuro. Mas esta ênfase pode também bloquear a resolução de novos desafios, e mesmo a de outros problemas do passado não resolvidos. Um exemplo é encontrado no Chile, onde as elites constataram que a divisão entre as forças de esquerda e as de centro estiveram na origem do golpe militar de Pinochet, e centraram-se apenas em superá-la, a ponto de deixarem intocados pontos centrais da institucionalização e do funcionamento da democracia como demonstra a persistência dos "enclaves autoritários", com as limitações constitucionais, a autonomia das forças armadas e a ausência de reparação às vítimas da ditadura.

Em outra ocasião (Krischke 1995) salientei que as abordagens da democratização que focalizam o comportamento das elites políticas tendem a considerar as orientações do eleitorado como um dado "fixo", que apenas reage à "accountability" das lideranças. Esta reação certamente existe, mas o comportamento e a cultura política da população também evolui paralelamente e merece estudo, como veremos adiante. Mais recentemente (Krischke 2000b; 2001) constatei também que o aprendizado político das elites tende a ser considerado numa concepção bastante estreita da racionalidade instrumental, que desconsidera as mudanças de valores, normas e objetivos que caracterizam os processos de democratização. 
McCoy sublinha nas conclusões do seu livro que o estudo do aprendizado político deverá centrar-se futuramente no "aprendizado complexo" dos novos valores, normas e objetivos da democracia:

(...) Os atores e agrupamentos políticos aprendem o comportamento democrático, seja porque valorizam as regras e normas democráticas em si mesmas, ou então porque as valorizam como os melhores meios do momento para a promoção dos seus próprios interesses privados (valorização instrumental da democracia). É certo que esta distinção trará consequiências para a sobrevivência e a própria natureza da democracia.

McCoy também salienta a necessidade de pesquisas sobre as mudanças da cultura política e da socialização política, que devem trazer novas "lições comparativas" acerca da transição política e do aprendizado político da democracia:

Como o aprendizado político das elites se traduz em aprendizado massivo? Embora este estudo não tenha considerado o aprendizado massivo, as teorias da hegemonia das elites, da mudança cultural, e dos processos de socialização serão úteis para passar a essa nova etapa. E também para saber sob que condições o aprendizado massivo pode direcionar o aprendizado das elites (...).

A compreensão das condições que produzem esses tipos diversos de aprendizado requer mais estudos de casos comparativos em contextos diferenciados, que incluam tanto as novas democracias que proliferam no contexto da globalização, como as democracias re-emergentes de ditaduras, ou ainda as democracias consolidadas, que estejam passando por turbulências e crises - como as que estão ocorrendo atualmente nos países centrais do Ocidente.

À luz do que vimos acima, seria lícito supor que o aprendizado político fosse um dos tópicos centrais dos estudos sobre cultura política na América Latina. Contudo isto não tem acontecido, uma vez que a literatura dessa área pouco tem tratado especificamente do tema. Quais as razões dessa lacuna? Sugeri anteriormente (Krischke 1999) que há um certo determinismo peculiar às teorias da modernização, que afeta a maior parte dos estudos sobre cultura política. Penso especificamente em uma forma de determinismo que considera a modernização como decorrente de forças externas que se impõem aos indivíduos, sem a mediação de processos de aprendizado em que estes estejam envolvidos como participantes ativos. Por exemplo, muitos estudos tendem a considerar o apoio à democracia como resultado de um "equilíbrio multicausal", mais ou menos espontâneo, entre o sistema sócio-cultural e o desenvolvimento políticoeconômico (Inglehart 1997). Tal suposição é também adotada por muitas interpretações sociológicas da democratização. (Lipset et al. 1993) 
Em suma, muitas das "grandes" teorias políticas e sociais sobre a modernização e a democratização mantêm supostos implícitos, e não demonstrados, acerca dos processos sócio-políticos de aprendizado que acompanham a mudança da sociedade e das instituições. Seria necessário "desmontar" essas teorias para constatar em que medida o estudo do aprendizado político confirma, modifica ou invalida esses supostos. Por exemplo, os estudos da cultura política geralmente referem a várias agências de socialização política (igrejas, escolas, família, mídia, grupos de idade, etc.) que seriam responsáveis pela diversidade entre as culturas e sub-culturas políticas. Assim, Inglehart (1997) atribui a tendência atual ao "pós-materialismo" entre a juventude à influência crescente da mídia (e a outros fatores econômicos e tecnológicos da "pósmodernização"). Em contraposição, afirma-se que a religião, a família e a escola estão perdendo a sua anterior centralidade nos processos de socialização. Mesmo reconhecendo a importância dessas mudanças, pouco se sabe sobre como e por que afetam a socialização política. Em outras palavras: como o deus ex machina da modernização/pós-modernização modifica a socialização e o aprendizado político?

Klaus Eder (2001) sustenta que "as sociedades aprendem mas o mundo é difícil de mudar". Um exemplo disso nos estudos de cultura política foi o apoio normativo crescente do público brasileiro à democracia, detectado por Moisés (1995). Partes do eleitorado declararam uma preferência crescente pelo regime democrático, e uma rejeição ao retorno do regime autoritário, apesar dos sérios problemas econômicos do país que prevaleciam naquela época. Simultaneamente, esses mesmos setores criticavam fortemente as falhas do desempenho governamental, a corrupção política, a falta de "accountability" das elites etc. Moisés denominou essa atitude crítica de "indignação republicana", pois aparenta fundar-se nos princípios e valores da democracia. Tal atitude parece similar à que Moreira (2000) constatou no caso mais atual e mais polarizado do Uruguai, entre um amplo setor (quase a maioria) do eleitorado, como sendo constituído de "democratas inconformados". Mas devemos perguntar se essas atitudes de inconformidade realmente representam casos de aprendizado político, e como afetam os processos de democratização.

Os resultados dessas pesquisas por survey são muito úteis para atividades de planejamento, as políticas públicas, campanhas eleitorais etc. Contudo é duvidoso que eles revelem muito sobre o aprendizado político, a cultura política como um todo, ou acerca das "bases sociais da legitimidade democrática" como queria Moisés. De fato é possível questionar se as técnicas de pesquisa por survey podem ter acesso ao "aprendizado complexo". O ponto aqui é que a mudança de valores políticos não pode ser inferida a partir de comportamentos e intenções declarados num contexto de resposta a questionários (Habermas 1990:104; Krischke 2000). Há diferentes níveis e ritmos de mudança na vida 
social, política, cultural e pessoal. Todos eles interagem, mas cada um deles requer análise específica.

Algumas de minhas pesquisas anteriores podem ser vistas como tentativas de encaminhar uma abordagem alternativa ao aprendizado político (Krischke 2001). Para isso é importante compreender o aprendizado político no contexto do que definimos por democracia. A "virada lingüística" de Habermas - e seus conceitos de "ação comunicativa" e "democracia como institucionalização de discursos" - oferecem um território comum para examinar as abordagens anteriores ao aprendizado político. Por exemplo, nesse novo contexto as teorias anteriores podem ser vistas de forma coordenada, e não apenas como propostas competitivas, ou excludentes umas às outras. Embora não se possa desenvolver aqui este argumento, ele visa superar alguns dos problemas principais da literatura sobre a democratização na América Latina (Krischke 1997; 2000b).

Por exemplo, aprendi com Habermas (1975) a distinguir entre a mudança na esfera motivacional e no âmbito da legitimação (e seus efeitos mútuos indiretos). Assim pude entender as diferentes conseqüências, em cada lugar, das ações das comunidades de base das igrejas e de outros grupos populares no Brasil, para a democratização política e sócio-cultural (Krischke 1990). Isto permitiu superar certas aporias da literatura anterior sobre as CEBs - que as viam seja como manifestação espontânea da modernização, seja como manifestação política deliberada na esfera pública.

Também interpretei como "ação comunicativa" (Habermas 1984-7; 1997) as várias interações entre atores sociais na constituição da esfera pública. Isto me permitiu entender os processos locais, nacionais e regionais de democratização através de uma perspectiva geral comparativa (Krischke 2001b). Esta perspectiva aborda comparativamente o aprendizado político como "desenvolvimento moral-cognitivo" (Habermas 1990). Tal desenvolvimento resulta de interações e da mútua constituição, histórica e intersubjetivamente situadas, entre os indivíduos, os atores/processos sociais e os atores/instituições políticos (Krischke 2000b; 2001b). Mas o mais interessante é que essa leitura da democratização é capaz de integrar as contribuições diferentes (e muitas vezes antagônicas) das várias abordagens ao tema - superando por exemplo, a antinomia entre "cultura versus instituições" levantada pelo debate entre as chamadas "análises do regime" e os "estudos culturais".

Tudo isso pode parecer demasiado ambicioso. Mas apenas indiquei nesses trabalhos a trajetória desta proposta, por uma nova abordagem ao aprendizado político, através de algumas evidências da sua manifestação local e nacional nos países da América Latina. A proposta deriva de uma fundamentação teórica 
coerente. As teorias de Habermas sobre a "ação comunicativa" e o "desenvolvimento moral-cognitivo" são multi-dimensionais, incluindo uma dimensão cognitiva (o desenvolvimento de visões do mundo), uma dimensão normativa (o desenvolvimento jurídico e moral), e uma dimensão subjetiva (o desenvolvimento de identidades e estruturas de personalidade mais complexas). As minhas pesquisas têm sugerido que o aprendizado político acontece em todas as três dimensões, através de processos históricos desiguais e diversificados, em cada dimensão.

Além disso, a definição de Habermas da "democracia como institucionalização de discursos" (Habermas 1979:73) supõe que "os discursos são institucionalizados à medida em que é criado um contexto social que permita acordos coletivos pós-convencionais, os quais por sua vez criam quaisquer estruturas compartilhadas pelos atores". Esta ênfase desloca o ônus da prova do aprendizado político a uma validação histórica intersubjetiva por parte dos atores individuais, sociais, e políticos - naqueles processos e instituições políticos que se disponham a criar e sustentar.

Esta mudança de paradigma (ou "virada lingüística") também conduz a um debate acerca da reconstrução da teoria democrática (Habermas 1997) no interior das ciências sociais na América Latina. Esta reconstrução busca recuperar e convergir contribuições alternativas das várias abordagens (em geral consideradas mutuamente excludentes). Isto é visto como parte do aprendizado político no exercício de nossa própria atividade profissional, durante as tentativas atuais de construir e fortalecer a vida democrática de nossas sociedades (Krischke 1997; 2000b). Encarei da seguinte maneira esse desafio, em uma revisão anterior das teorias da democratização na América Latina:

(Esta é uma) resenha comparativa dos estudos sobre os processos de democratização na Améri-
ca Latina, focalizando principalmente os que tratam das transformações atuais da cultura políti-
ca dos públicos massivos (autodenominados "culturalistas"), e outros que abordam o compor-
tamento das elites sob o prisma da escolha racional (considerados "racionalistas"). A resenha
argumenta que há entre essas duas abordagens excludentes uma crescente convergência temáti-
ca, relacionada com seus respectivos desdobramentos internos e com sua competição na Améri-
ca Latina com novas correntes de interpretação, que lhes são limítrofes e/ou alternativas. Tudo
isso tem suscitado interfaces emergentes e inovadores desafios à pesquisa nessa área de estudos
(Krischke 1997).

O que vimos até aqui não chega a tratar o aprendizado político no âmbito da globalização, embora este esteja implícito na orientação comparativa que propomos de sua experiência nas várias esferas nacionais. Na verdade, existem sub-temas do aprendizado político que constituem "interfaces temáticas" (Krischke 2000b) entre as diferentes abordagens na literatura, as quais se aplicam diversamente às situações nacionais no contexto da globalização. A minha proposta é realizar uma avaliação dessas diferentes contribuições de cada abor- 
dagem para os temas comuns em estudo, e dos problemas e limitações conceptuais que deixam em aberto para pesquisas futuras.

Uma primeira interface focaliza o "aprendizado organizacional", experiência que é diversamente enfatizada por Jennifer McCoy (2000) e por Klaus Eder (2001). O que atrai atenção para esta temática é a influência atribuída às chamadas "comunidades epistêmicas" sobre o desenvolvimento institucional (Haas 1991). Seria necessário conhecer se essa influência colabora para institucionalizar novas visões do mundo, e avanços cognitivos inovadores, através do aprendizado político das elites, e quem sabe também entre os públicos massivos - por exemplo, através de processos como os que Habermas (1997) denominou "juridificação das relações sociais".

Sem dúvida estes processos de institucionalização são reconhecidamente ambíguos, por implicarem uma "colonização" da vida cotidiana através de procedimentos administrativos. Contudo, a ênfase nas "comunidades epistêmicas" potencializa sua penetração na dinâmica da sociedade civil, onde a criação de novos conhecimentos permite a expansão democrática participativa. Um exemplo notório dessas possibilidades na atual etapa de globalização tem sido a crescente legitimidade dos tribunais internacionais para julgar a violação dos crimes contra a humanidade, os direitos humanos, genocídio etc. Vários autores estão trabalhando esta temática, entre os quais March (1991), Strydom (1993), Wynne (1992) e Reiter (1994).

Por outra parte, também ao nível local e âmbito municipal é possível observar a importância da juridificação das relações sociais sob a influência de comunidades epistêmicas. A minha atual pesquisa (Krischke 2002) constatou marcadas diferenças entre a socialização da juventude nas cidades de Curitiba e Porto Alegre, devida às influências das administrações de partidos diferentes nessas cidades, aparentemente relacionadas à filosofia da educação adotada pelas associações de professores, sobre o currículo escolar da rede de ensino municipal e outros dispositivos de juridificação. Por certo, esses não são os únicos fatores que influem nas diferenças dos processos de juridificação nas duas cidades, mas sugerem a importância das comunidades epistêmicas na sua implantação.

Outra linha clássica de estudos a ser reconsiderada é a abordagem dos processos de "socialização política". Um aspecto central desta literatura é o caráter reflexivo espontâneo que alguns autores atribuem aos indivíduos participantes na sociedade globalizada (Giddens 2000; Beck 1992). Seria esse processo caudatário da "virada lingüística" (Searle 1995) ou talvez apenas um novo nome para os esquemas hiper-generalizantes das teorias da modernização? No 
primeiro caso, como se relacionaria aos conceitos de "pessoa moral" (Rawls 1999) e "desenvolvimento moral-cognitivo" (Habermas 1990), sem recair numa filosofia da história ou do sujeito, centrada nas tradições liberais do Ocidente?

O ponto sublinhado por Eder é que o "mundo é difícil de mudar". Se consideramos simplesmente as agências usuais de socialização como foco do aprendizado político pouco podemos garantir com a sua mudança. Afinal, a mídia internacional tem sido o principal instrumento usado pelo terrorismo desde 11 de setembro, e a censura (ou autocensura) prévia não constitui imunidade a essa utilização. Também as escolas de quadros disseminadas por Bin Laden no Paquistão e outros países podem até ser destruídas, mas isso não significará a total neutralização do terrorismo (embora colabore para a sua redução atual).

O ponto central é como assegurar a existência de uma esfera pública plural, de âmbito internacional, que permita a inclusão da diferença e a resolução negociada dos conflitos. Os processos de socialização política democráticos só serão possíveis com alcance global, mediante a participação nessa esfera pública. Vários autores oferecem contribuições relevantes ao debate, entre eles Rawls (1999), Connover e Searing (1994), Ikenberry e Kupchan (1991), Mann (1990), Corsten (1998), Heiskala (1997) entre outros. Klaus Eder (2001) é quem mais tem trabalhado esta temática no contexto do aprendizado político. Mas será importante também constatar o que os críticos "comentaristas" de Rawls e de Habermas têm a dizer sobre os processos de socialização no âmbito da globalização (Taylor 1998; Walzer 1999).

Os exemplos de minha pesquisa atual (Krischke 2002) também demonstraram profundas transformações da cultura política em Porto Alegre, que se articulam com processos de aprendizado político globalizantes - tais como os efeitos dos "Fóruns Sociais Mundiais" realizados naquela cidade, ou ainda com o acesso cotidiano da população em geral a programas culturais de âmbito internacional (festivais de cinema, teatro, música etc.). Tais mudanças também se relacionam com outros processos participativos municipais e comunitários, que têm sido mais estudados e divulgados (como o debate público do orçamento municipal, por exemplo). Em suma, o exame dos processos atuais de socialização política necessita incluir tanto os fatores de expansão da esfera pública em âmbito internacional, quanto aqueles referentes à experiência comunitária e ao espaço político local - dando a cada um deles o seu crédito e estabelecendo o seu significado.

Finalmente, há uma vasta literatura sobre a "ética do discurso", que lançou originalmente luz sobre as contribuições de Jürgen Habermas, e da qual Eder derivou criticamente sua linha de pesquisa sobre o aprendizado político, desde um ponto de vista sociológico. Penso que essas contribuições devem ser com- 
paradas às de Honneth (1995), Gunther (1993) e Bohman e Rehg (2001) de modo a extrair suas consequiências práticas no contexto da globalização. A ênfase previamente transcendental dessa linha de estudos, no âmbito da Filosofia Moral, teve o mérito de relacionar as questões referentes ao aprendizado aos contextos metafísicos e religiosos que usualmente fundamentaram os discursos (senão a prática) da política no mundo inteiro.

Ainda hoje, tanto tempo após os eventos de 11 de setembro de 2001, constata-se que a mídia e os discursos oficiais estão perigosamente impregnados de uma mística de "guerra santa" que se supunha erradicada da experiência ocidental, pelo menos nas últimas décadas. Contudo, há um contexto dito "pósmoderno" que também favorece o exame da irracionalidade, enquanto oferece a crítica relevante das "Grandes Narrativas" da modernidade (como prisioneiras de uma metafísica teológica). Vários dos autores já citados colaboram para integrar e superar essas limitações no debate sobre a ética dos discursos. Alguns outros referem-se especificamente a temas relacionados ao aprendizado político, como nas contribuições de Amato (1998), Enders (1996), Anderson (2000) e Strike (1994).

A minha própria pesquisa atual (Krischke 2002) assinalou que as diferenças encontradas entre os processos de socialização política nas cidades de Curitiba e Porto Alegre remetem à diversidade dos discursos éticos e políticos adotados por nossos entrevistados para justificar (ou criticar) os efeitos da modernização. No caso de Porto Alegre, por exemplo, há uma prioridade atribuída à justiça social, que percorre como fio condutor a discussão dos demais temas. Em Curitiba isso não acontece, e a modernização da cidade aparece como um processo inevitável, onde temas como a violência urbana e a injustiça social aparecem sob forma "naturalística" - como no restante do país. Por certo, essas diferenças relacionam-se com os discursos políticos oficiais, dos partidos e administrações públicas que têm exercido o poder nessas cidades. Mas também referem ao plano da experiência histórica anterior e das tradições culturais, presentes de modo variável no cotidiano dos entrevistados, seus valores e práticas, religiosas e de outro tipo.

Certamente não se trata aqui de propor o retorno a uma filosofia da história ou da consciência, antes o contrário - ou que a democratização e a globalização possam apenas ser compreendidas através de um conceito metafísico da humanidade e de seu destino. As nossas pesquisas estão mostrando exatamente o oposto disso. O que estamos constatando, isto sim, é que a globalização, como a democratização, são processos históricos de aprendizado de novos valores, atitudes e comportamentos sócio-políticos que capacitam as pessoas, grupos e indivíduos a criar e a sustentar um novo modo de vida, e novas instituições que 
organizem e administrem esse mundo vivido. Essas mudanças apóiam o ingresso gradual de novos atores sociopolíticos na esfera pública, tornando-a crescentemente inclusiva e abrangente. Há um trabalho enorme a fazer nesses estudos, inclusive apenas para mostrar inicialmente que esse processo histórico de aprendizado político pode ser compreendido de uma perspectiva geral, que seja tanto comparativa como universalista.

\section{Referências Bibliográficas}

Amato, P. (1998). Communicative ethics and deliberative democracy: between rationale and rationality. Fordham University.

Anderson, J. (2000). The 'third generation' of the Frankfurt School. Intellectual History Newsletter, 22.

Beck, U. (1992). Risk society: towards a new modernity. New York: Sage. (2000). The cosmopolitan perspective: sociology of the second age of modernity. British Journal of Sociology, 50(1), p. 79-105.

Bohman, J. (1996). Public deliberation: pluralism, complexity, and democracy. Cambridge: MIT Press.

e B. Rehg (2001). Pluralism and the pragmatic turn: thetransformation of Critical Theory. Cambridge: MIT Press.

Conover, P. J. e D. Searing (1994). Democracy, citizenship and the study of political socialization In: Budge e D. Mckay. Developing democracy. New York: Sage.

Corsten, M. (1998). Between constructivism and realism: Searle's theory of the construction of social reality. Philosophy and the Social Sciences, 28.

Eder, K. (2001). As sociedades aprendem mas o mundo é difícil de mudar. Lua Nova Revista de Cultura e Política, 53, p. 5-28.

Enders, B. (1996). Habermas and critical thinking. In: Philosophy of Education (Yearbook).

Giddens, A. (2000). Runaway world: how globalization is reshaping our lives. New York: Routledge.

Gunther, K. (1993). A sense of appropriateness: application discourses in morality and law. Albany: Suny Press.

Haas, E. (1991). Collective learning: some theoretical speculations. In: G. Breslauer and P. Tetlock. Learning in U.S. and Soviet Foreign. Boulder: Westview.

Haas, P. (1992). Epistemic communities and international policy coordination. International Organization, 46.

Habermas, J. (1975). Legitimation crisis. Boston: Beacon Press. (1979). Communication and the evolution of society. Boston: Beacon Press. 
(1984-7). The theory of communicativeaction. Boston: Beacon Press, 2 v.

(1990). Moral consciousness and communicative action. Cambridge: MIT Press.

(1997). Between facts and norms: contributions to a discourse theory of law and democracy. Cambridge: MIT Press.

Heiskala, R. (1997). Society as semiosis. University of Helsinki.

Honneth, A. (1995). The struggle for recognition: the moral grammar of social conflict. Cambridge: Polity Press.

Ikenberry, J. e C. Kupchan (1990). Socialization and hegemonic power. International Organization, 48(2), p. 279-312.

Inglehart, R. (1997). Modernization and postmodernization: cultural, economic and political change in 43 societies. Princeton: Princeton University Press.

Krischke, P. (1990). Church base communities and democratic change in Brazilian society. Comparative Political Studies, 24(2), p. 186-210.

(1995). Brasil: democracia delegativa? In: C. Pinto e H. Guerrero. América Latina: o desafio da democracia nos anos 90. Porto Alegre: Edufrgs.

(1997). Cultura política e escolha racional na américa latina: interfaces nos estudos da democratização. BIB Revista Brasileira de Informação Bibliográfica em Ciências Sociais, v. 43: 103-126.

(1999). Contextos de socialização, desigualdades e diferenças na democratização: revisando a teoria de R. Inglehart sobre a mudança cultural. In: Anais do Seminário Internacional por uma Cultura da Paz. Curitiba: Unesco/Ufpr.

(2000). Participação social e cultura política. Revista de Administração Municipal-Municípios, Ibam, 45(224), p. 12-18.

(2000b). Problems in the study of democratization in Latin America. In: International Sociology, 15 (1), p. 107-125.

(2001). Aprender a democracia na América Latina: notas sobre o aprendizado político e as teorias da democratização. In: H. Leis et al. Modernidade crítica e modernidade acrítica. Florianópolis: Cidade Futura.

. (2001b). The learning of democracy in Latin America: social actors and cultural change. Huntington: Nova Science Publishers.

. (2002). Relatório de pesquisa ao CNPq, jun.

Lipset, S. M. et al. (1993). A comparative analysis of the social requisites of democracy. International Social Science Journal, 136, p. 155-175.

Mann, D. (1991). Environmental learning in a decentralized political world. Journal of International Affairs, 444 (winter).

Mccoy, J. (2000). Political learning and democratization in Latin America: do politicians learn from crisis? Coral Gables: North-South Center. 
Moisés, J. A. (1995). Os brasileiros e a democracia. Bases sociais da legitimidade democrática no brasil, São Paulo: Ática.

Moreira, C. (2000). Cultura política no Uruguai ao final do século: a democracia dos inconformados. In: P. Krischke. Ecologia, juventude e cultura política. Florianópolis: Edufsc.

Rawls, John (1999). Law of peoples. Harvard: Havard University Press.

Searle, J. (1995). The social construction of reality. New York: Free Press.

Strike, K. A. (1994). Discourse Ethics and Restructuring. In: Philosophy of Education (Yearbook).

Strydom, P. (1993). Sociocultural evolution or the social evolution of practical reason. Eder's critique of Habermas. Praxis International, 13.

Taylor, C. (1998). Multiculturalismo (examinando a política do reconhecimento). Lisboa: Instituto Piaget.

Walzer, M. (1999). Da tolerância. São Paulo: Martins Fontes.

Wynne, B. (1992). Risk and social learning: reification to engagement. In S. Krimsky e D. Golding (orgs.). Social theories of risk. New York: Prager. 